\title{
María, virgen y madre, formó su humanidad en la gracia*
}

\author{
P. Samuel Forero Buitrago, O. P.**
}

\begin{abstract}
Resumen
en este artículo el autor parte del reconocimiento de la propia humanidad de María y de sus rasgos característicos como virgen y madre. este reconocimiento se constituye en una clave importante para una lectura que tiene en cuenta la pobreza de una mujer que hizo posible la obra de Dios en la historia de la salvación. ella no requiere de un cúmulo de títulos para exaltar y honrar su nombre, su única riqueza se halla en el reconocimiento de su humanidad redimida por Cristo. ella se convierte en la madre de los hombres como la primera creyente. Este estudio reflexiona sobre algunos rasgos antropológicos reconocidos en María, los cuales resitúan y redefinen la problemática de la mariología en su desarrollo histórico, estos también constituyen un hecho significativo para la reflexión teológica posterior.
\end{abstract}

Palabras clave: María, virgen, madre, mujer, pobreza, humanidad, creyente.

* Forero Buitrago, S. (2012, 19 de sep.). Conferencia inaugural. en III Congreso Internacional de Teología Mariana. Chiquinquirá, BOy: Facultad de Teología de la Universidad Santo Tomás.

** Doctorando en Teología Moral por el Instituto Católico de París. Magíster en Hermenéutica Bíblica de la Universidad de Antioquia (Medellín). Decano de División de Ciencias Teológicas y Decano Académico de Teología de la Universidad Santo Tomás. Correo electrónico: sabosi@hotmail.com 
María se muestra en su multiforme pobreza cercana a la experiencia real del pueblo y de los fieles. Su experiencia de fe y de vida estuvo marcada por las situaciones reales de los suyos, de su familia, de su contexto, sobre todo de su rol particular como mujer y madre. es necesario que no pase desapercibida la historicidad real de María, pues "la humanidad de María implica su pertenencia a un pueblo particular, el pueblo judío" (Groupe des Dombes, 1999, p. 72). En el Evangelio de san Lucas, ella misma se define como esclava y pobre (Lc 1,38 y 48). Más aún, su manera de actuar está sumida en la total reflexión: "Todo esto lo meditaba en su corazón" (Lc 2,19). Con su pobreza halló gracia delante de Dios.

A partir del reconocimiento de su propia humanidad y de sus propios límites, María, virgen y madre, como en una especie de afirmación de vaciamiento interior, de pobreza, de disponibilidad total, fue capaz de reconocer la grandeza y el poder de Dios. ella se mostró disponible a una obra que solamente la fe puede dar. ella se dispuso a ser la esclava del Señor en una dimensión de fe que posibilitó entonces el punto de partida del nacimiento de lo divino, de la encarnación, de hacer la voluntad de Dios, del Sí (Fiat). Estos rasgos antropológicos reconocidos en María resitúan y redefinen la problemática de la mariología y constituyen también un hecho significativo para la reflexión teológica posterior.

María virgen y madre del Redentor es la mujer de su tiempo en la historia de la salvación. ella no requiere de un cúmulo de títulos para exaltar y honrar su nombre, su única riqueza se halla en el reconocimiento de su humanidad redimida por Cristo. ella es así la primera redimida por el Señor, pues llevó en su seno santísimo al mismo autor de la redención. Schillebeeckx afirma:

Por única que sea María y por muy universal que sea su papel en el plan divino de la salvación, sigue siendo verdad, que todos los hombres, con excepción de Cristo, el Dios-Hombre y Redentor, son esencialmente personas redimidas" (1969, p. 10).

María, por ser la madre del Señor, no se excluye de esta gracia de redención; por el contrario, ella es la primera redimida.

A partir de este acercamiento de una lectura histórica de María y de su total confianza en Dios, que el cántico del Magnificat ya proclama, consideraré 
tres puntos básicos sobre la mariología, los cuales abren de alguna manera el contexto de la problemática de este III Congreso Internacional de Teología Mariana:

1. María, la sierva del Señor.

2. María, madre de los creyentes.

3. María, un cántico de exaltación.

\section{María, la sierva del Señor}

María no ejerció ningún oficio relevante en el marco del pueblo de Israel. Su nombre indicaba la referencia de un nombre común el cual lo llevaron muchas mujeres de su tiempo, como María la hermana de Marta, María la madre de Santiago o María Magdalena. Péguy evocaba a María como "una pobre judía de Judá y como la más humilde de las creaturas" ${ }^{11}$ (Groupe des Dombes, 1999, p. 72). Esta pobreza no es otra cosa que la confianza en Dios, traducida en una total fidelidad. María, "a pesar de la humildad y pobreza de su vida, Dios ha puesto su mirada en ella y por eso será llamada dichosa. Dios se sirve muchas veces de lo sencillo y humilde para hacer presente su salvación en la historia humana" (Guijarro y García, 1995, p. 194). La pobreza de este primer momento contenida en el ser de María, en el reconocimiento de su propia vaciedad frente al Dios Altísimo, no es la pobreza alienante que daña y frustra el futuro inmediato de una persona. es más bien el reconocimiento de considerarse como una obra de barro que será moldeada y hecha por Dios. es la conciencia del límite de la creatura frente al Creador o de una vida dedicada a Dios.

este reconocimiento antropológico de despojo personal frente a la presencia de Dios es un acto de aceptación total de María de hacer siempre la voluntad de Dios y de no poner obstáculos a esta pedagogía divina. en este aspecto es necesario afirmar la realidad objetiva del crecimiento y del desarrollo de la fe de María desde el momento mismo del anuncio del Ángel en la Encarnación del Hijo de Dios (Schillebeeckx, 1969, p. 40). Este crecimiento

1 Traducción hecha del francés. 
de fe en María, nos dice Schillebeeckx, fue el resultado de su íntima cercanía y cotidiana asociación con su Hijo en el progresivo conocimiento de la revelación de su misterio.

De aquí se desprende entonces que la obra de María y de su vida personal no puede ser leída o estar disociada de la obra de Cristo. La mariología está íntimamente ligada a la cristología, y por tanto no se puede comprender la persona de María sin referencia total y directa a la persona de Cristo. Desde esta clave hermenéutica, las pobrezas de María como mujer y madre inserta en la historia particular de su pueblo alcanzan un valor histórico, psicológico y religioso muy importante, sobre los cuales no voy a profundizar. Además de esta actitud interior de pobreza en María, quien tiene un corazón de pobre a semejanza de otros justos del Nuevo Testamento como zacarías, Isabel, Simeón, Ana, etc., también se suman otras alocuciones bíblicas que hacen referencia a otro tipo de pobreza que reclama justicia.

La situación social que vive María no es la de una familia de potentados. Los lugares descritos por los textos bíblicos se familiarizan siempre con la pobreza y la sencillez. Son lugares sin gloria. Su esposo José es un artesano carpintero que vive en Nazaret alejado de la gran ciudad, Jerusalén. Al lado de todas estas situaciones, el cántico del Magnificat en su segunda parte (Lc 1,50-53) da cuenta de todos estos hechos en un paralelismo antitético en donde se pueden ver con claridad los ricos y los pobres, los poderosos y los humildes, los que cuentan y los que son despreciados. Así,

los pobres y humildes de los que habla María son los que solo cuentan con Dios en su corazón, todos aquellos a los que el Salmo 34 cita como los pobres de yahvé: los humildes, los que temen a Dios, los que se refugian en él, los que le buscan, los corazones quebrantados y las almas oprimidas (Descalzo, 1992, p. 104).

esta segunda parte del cántico es llamada también canto de pobreza y allí se registra la existencia de un grupo que es reconocido plenamente por Dios, los pobres, los anauim. y María se hace entonces la sierva del Señor en total consonancia con los pobres de yahvé. en contraposición a los pobres están los que detentan las grandezas humanas, los cuales están en conflicto con Dios: el orgullo (Lc 1,50-51), el poder (52), y la riqueza (53). Pero Dios invierte las situaciones (Gélin, 1994, p. 74) porque se apiada de los pobres. María 
con su canto da la bienvenida a la realización comunitaria de salvación. Su canto es el himno también de la Iglesia que le recuerda su acción profética de anunciar la liberación mesiánica y la reconciliación de los hombres entre sí.

$\mathrm{Al}$ respecto, y a modo de recordación, es necesario reconocer el esfuerzo de las reflexiones teológicas de la teología de la liberación y las constantes apreciaciones que la religiosidad popular nos ofrece con respecto a los pobres. También las investigaciones del feminismo que hasta el momento han tratado sobre esta problemática. Todo ello tiene algo que decirnos de la figura de María a través de los siglos.

La teología vive y se sustenta de la vida de fe que llevan los miembros de la comunidad de la Iglesia. y los teólogos deberían experimentar que esta vida es más poderosa que todos los débiles esfuerzos llevados a cabo por la teología (Schillebeeckx, 1969, p. 12).

en todo caso, vale la pena interrogarnos: ¿qué contenido teológico sobre María brindamos a nuestros creyentes que frecuentan nuestros santuarios marianos y cristológicos? ¿qué imagen de María predomina en nuestra concepción de fe? ¿Cuál es nuestro grado de compromiso con los pobres y los humildes?

\section{María, madre de los creyentes}

Una de las diferencias principales con respecto a las demás mujeres del tiempo de María es que ella vivió como mujer la experiencia de virgen y madre. Como virgen es, de alguna manera, la evocación veterotestamentaria para calificar y personificar al pueblo de Israel: "La virgen hija de Sion" (2 R. 19,21). Como madre, esta interpretación se hacía en una doble definición. En primer lugar, a Sion se le reconocía como la madre de las naciones reunida en un único pueblo de Dios (Salmo 137,8), que luego será Jerusalén quien reciba esta denominación, como la madre de una posteridad numerosa (Is. 54,1-3). en segundo lugar, se reconoce como la mujer embarazada que trae al mundo un niño (Is. 66,7-13), lo cual es la personificación del pueblo entero (Grelot, 1984, p. 411). en este sentido, María es reconocida en su humanidad 
como la representación de un pueblo con un significado de salvación y al mismo tiempo en quien se obra la recepción del Salvador.

María es considerada también como la mujer que podía disponerse en matrimonio para transmitir la vida. La virginidad no era para los judíos un objetivo en sí mismo, sino una disposición total de la persona para la fecundidad como bendición. Sabemos también, por los escritos bíblicos, que la tensión que habitaba en muchas mujeres contemporáneas de María era el deseo y la esperanza de dar la vida al Mesías. De este modo, para cualquier mujer la experiencia de la esterilidad, como oposición a la fecundidad, era una maldición que cerraba las puertas a la vida y a la perpetuidad del pueblo elegido. "el hecho de la virginidad de María en la concepción de Jesús se afirma en Mt 1,18-23 y Lc, 26-38" (George, 1993, p. 509), de igual manera se subraya la virginidad como un hecho fundamental para la filiación divina de Jesús.

Desde el inicio del cristianismo, la Iglesia en su experiencia de fe reconoció en María la maternidad del Hijo de Dios. El nombre de Théotokos es la constatación de la afirmación de su misión respecto a Cristo.

Lentamente el concepto de madre nuestra brota de la reflexión teológica. San Ireneo observa que María es como eva que regenera a los hombres en Dios. La idea de madre de la nueva generación de vivientes permanecerá desde entonces constante (Ossanna, 1988, p. 1205).

es de reconocer también un nuevo acento que es puesto en María, en un sentido de universalidad, como madre común, pues ya en el siglo X Juan el Geómetra afirma que

María no es solamente la madre de Dios, sino nuestra madre común, porque ella profesa a todos los hombres afecto e inclinación [...] y toma a todos en sus brazos, y la llama "la nueva madre común" [...], madre de todos nosotros juntamente y de cada uno. San Bernardo dice: la madre de Dios es madre nuestra (citado en Ossanna, 1988, p, 1205).

es importante saber que los evangelistas no presentaron a María en sus grandezas y exaltaciones, sino que la dejan ver como la primera creyente. Los textos bíblicos nos dejan ver claramente que desde el inicio podemos encontrar en María un sí de creyente, pues ella se mostró desde el principio 
como la mujer que fue obediente a Dios en una aceptación total del plan de Salvación. Augustin George afirma: “Los evangelistas, lejos de hacer consistir la grandeza de María en luces excepcionales, la muestran en su fe, sometida a las mismas oscuridades, al mismo proceso que el más humilde de los fieles (Lc 1,45)" (1993, p. 511).

el Pueblo de Dios antes que todo es una comunidad de creyentes. y esto aparecerá como típico en la fe de la persona en la que quede personificada la fe de todo el pueblo. Como nos lo recuerda la Lumen Gentium, ella es madre de la Iglesia y madre de los hombres. María como madre de los hombres es la primera creyente y a la vez la madre de los creyentes que va a ser recordada por generaciones de generaciones. Su ejemplo de madre que abraza en su corazón la obra de Dios nos enseña que su papel no es estrictamente de la mediación redentora reservada exclusivamente a Cristo, sino que su mediación está dada en la solidaridad de enseñarnos a reconocer a Cristo. Consagrarnos a ella no es más que una manera excelente de consagrarnos a su Hijo. En este sentido de mediación, desde unas características bíblicas, María permite que todos los hombres que buscan a Dios participen de esa solidaridad: "La 'mediación' de María ha de entenderse en el plano de la solidaridad de todos los hombres necesitados de la gracia" (Schmaus, 1973, tomo IV 4, p. 437).

\section{María, cántico de exaltación}

el Magnificat se inscribe en la liturgia cristiana como un cántico de alabanza de María que recoge la esperanza, la luz y los dones mesiánicos prescritos en el Antiguo Testamento. Su estructura y elementos esenciales se inspiran en el cántico de Ana (1 S 2,1-10) y de otros pasajes de la escritura en una acción de gracias. Las gracias proclamadas por María se relacionan con Abraham, el padre de los creyentes, y entre ellos dos aparece con fuerza la comunidad de los pobres, de los predilectos y los salvados por Dios (Lc 1,50-54). Desde ese momento este cántico también es el anticipo de las bienaventuranzas.

María se descubre entonces como un cántico de exaltación, de alabanza a Dios. en este sentido, la Iglesia en su liturgia se une a ese primer momento fecundo de María, quien por su boca canta a Dios la acción de gracias del 
pueblo de Israel. en consecuencia, la Iglesia encuentra en esta alabanza el mejor ejemplo de su liturgia y es allí donde quizás la Iglesia reconoce con mayor claridad a María como su madre (O’Donnell y Pié-Ninot, 2001, p. 698), ya que en Cristo recibe su origen y su eficacia. En la Iglesia ortodoxa la devoción mariana es esencialmente litúrgica:

evocar a María, Madre de Dios, lleva a contemplar su misterio en la oración litúrgica o privada en unión estrecha con Cristo y en la memoria de los acontecimientos de la salvación. María tiene un lugar eminente con respecto a los otros seres creados y ella es orada y cantada con fervor por los fieles ${ }^{2}$ (Jeanlin, 2012, p. 9).

Desde estos elementos esenciales de la tradición eclesial y de los relatos bíblicos, aportaremos algunos elementos nuevos para clarificar cuál es la liturgia celebrada y rendida a María.

Con justa causa fue a partir del siglo II que comenzó el culto a María después de la celebración de los mártires en el ciclo de los santos. ello se explica por el hecho del recelo de los primeros cristianos de identificar, dentro del contexto sociocultural y religioso del momento, a María como una diosa. María no era una diosa del mundo mediterráneo helenizado a quien se le podían rendir los mejores honores humanos. De esto se desprende que la celebración tardía de las fiestas marianas de raigambres bíblicas y doctrinales no puede ser relacionada con un pasado pagano. También vemos que algunos elementos litúrgicos con referencia a María son tardíos, pues hay que esperar hasta el siglo IV para nombrar a María en el canon de la misa (Laurentin, 1985, p. 459); y las primeras oraciones en occidente dirigidas a María no datan sino hasta la mitad del siglo V. Los evangelios son parcos en hablar de María y solamente es Lucas quien la pone a la luz pública. Por otro lado, desde el texto bíblico, notamos que el evangelista Lucas pone en claro cuál es la justa causa de alabanza de María: "porque Dios ha puesto los ojos en la humildad de su esclava, por eso desde ahora todas las generaciones me llamaran bienaventurada" (Lc 1,48). Su humildad y sencillez alcanzó gracia ante Dios. En este sentido, ser esclava del Señor significa que

2 Traducción hecha del francés. 
María de Nazaret es la creyente y la esclava modelo que responde con todo el corazón al plan de Dios, y es también la precursora de la galería de gentes de mala fama, es decir, de mujeres, de pecadores y gente sencilla, de los que nadie esperaría que respondiesen favorablemente a la revelación de Dios (Brown, 2004, p. 141).

en este doble movimiento de reconocimiento y exaltación de María en el Magnificat, podemos ver a una mujer de su tiempo y a una mujer en particular en un momento histórico que discierne y hace la voluntad de Dios. ¿La imagen de mujer que tenemos de María en la Iglesia se identifica realmente con María, la madre de Jesús de Nazaret? La tentación de los cristianos a través de la historia es intentar mostrar una figura de María inflamada y enaltecida a raíz de nuestros propios poderes e intereses, hasta tal punto de rendirle culto y de divinizarla. Durante épocas la Iglesia ha tenido que hacer el esfuerzo de purificar la imagen de María:

eso llevó poco a poco a precisar en qué sentido la Virgen se honra como Madre de Dios, y a distinguir el culto de adoración (latría) debido a Cristo del honor que se rinde a las criaturas [...] Por esta razón, en su rigor, el creyente "no ruega" a María, sino se encomienda a su oración: "Santa María, Madre de Dios, ruega por nosotros [... $]^{3}$. (Jourjon, 1998, p. 714).

Bien lo señala santo Tomás cuando se refiere a la adoración (latría), indicando que es exclusiva para adorar a Dios y no a la creatura. en este sentido, por el hecho de que María es ser creatura racional, a ella le rendimos veneración de dulía, y por su dignidad de ser la Madre de Dios le brindamos una veneración de hiperdulía (ST, III, q. 25, a. 5).

Al respecto, quiero traer una reflexión muy válida de Schillebeeckx con respecto a conferir falsos títulos a María, hecho que se dio en la edad Media con la pretensión de honrar a María con más de mil nombres, cosa que es inoficiosa; pues dice el teólogo dominico que ella está suficientemente honrada con los gloriosos títulos que son suyos de veras.

3 Traducción hecha del francés. 
Como ejemplos, citaremos al seudo-Alberto: 'No pretendemos adornar a la gloriosa Virgen con nuestras mentiras'. San Bernardo dice: "el honor de la Reina exige únicamente fidelidad; la Virgen regia no necesita falso honor, ya que está abundantemente dotada de verdaderos títulos de honor y adornada con la corona de muchas glorias. y San Buenaventura: “No deberíamos inventar nuevos títulos de honor en alabanza de la Virgen, la cual no necesita nuestras mentiras, ya que está ricamente adornada de verdadera gloria"[...] (1969, p. 13).

en este contexto y más recientemente,

en su discurso pronunciado en víspera del Congreso Mariano celebrado en Roma en noviembre del año 1954, el papa Pío XII advertía también a sus oyentes del peligro de exageración que puede haber en nuestra actitud hacia María (en el estudio teológico, en el fomento exagerado de devociones o en el puro sentimentalismo). y señaló también el peligro de empequeñecimiento del misterio mariano por una racionalización extrema (2000, pp. 40-41).

De esto podemos concluir que es necesario como creyentes revisar nuestra manera de dirigirnos y de honrar a la Santísima Virgen, no con suspiros y falsas devociones, sino uniéndonos a su intercesión ante Dios a la cual está ella siempre solícita.

en efecto, cabe destacar que nuestra oración mariana va dirigida a Cristo en donde el creyente, en sus iniciativas y en su experiencia particular de fe, ora a Dios por medio de María, pidiendo “¡Hágase tu voluntad!”. Por ejemplo, "[el] valor de la oración del rosario consiste en su concentración sobre el misterio salvífico de la redención. Pero María está activamente presente en y asociada con todo el conjunto de este orden histórico de la salvación" (Schillebeeckx, 2000, pp. 40-41). y continúa: “en realidad, no hay verdadera diferencia entre la forma psicológica de la oración del rosario y la de la oración del breviario. Las dos son formas vocales de oración y, al mismo tiempo, son una oración interior" (1969, p. 248).

Finalmente, es interesante saber que la oración cristiana durante siglos ha recogido del Antiguo Testamento algunas imágenes bíblicas para realzar la figura de María, especialmente para evocar sus virtudes y su misión. 
Prueba de esta constatación son las letanías lauretanas a la Virgen María que datan desde 1587. Las comparaciones allí contenidas y tomadas de los grandes momentos de la historia de fe del pueblo de Israel expresan esta continuidad en la persona de una mujer elegida por Dios, figuras tales como: arca de la alianza, espejo de justicia, trono de la sabiduría, torre de David, puerta del cielo, etc. estos atributos comparativos puestos en María la hacen merecedora de ser "puente de unión entre el Antiguo y el Nuevo Testamento" (1994, p. 70) como bien lo afirma Albert Gélin, de igual manera, ella es el centro donde confluyen los ruegos de los orantes de la tradición cristiana:

María será el eco instantáneo de una larga cadena de orantes: su espíritu refundirá todo el deseo de recibir al Dios que se aproxima y resumirá toda esta esperanza que constituye la dimensión espiritual de Israel que, por fin, va a engendrar a Cristo (1994, p. 70).

Así pues, en María, en su humanidad, encontramos la expresión más límpida de un cántico de exaltación que ella misma hace en su vida de creyente para la humanidad. en palabras del mismo autor, “María averigua cuáles son nuestras necesidades y, con franca sencillez de una madre, se las presenta a Dios, quien en Jesús, fue y sigue siendo su Hijo" (Gélin, 1994, p. 70).

\section{Para puntualizar}

Luego de haber expuesto algunos elementos esenciales de la mariología, especialmente aquellos que conciernen al conocimiento y a la veneración de la Madre del Salvador, quiero ahora puntualizar sobre el título del presente Congreso de Teología Mariana, el cual aborda la problemática titulada: María, madre y hermana de los pobres.

Un buen comienzo académico es señalar desde ahora la necesidad de distinguir la relación existente entre los dos calificativos de madre y hermana dados a la Virgen María. en principio y en el orden de la genealogía, la relación de madre y hermana a nivel humano puede ser sospechosa porque se detentan dos relaciones asimétricas muy diferentes e inconciliables en una misma persona. La primera, señala la causa o el origen de algo, el cual le corresponde en este caso al apelativo de madre; y el segundo, en una relación 
proporcionada, la correlación de hermano. San Lucas nos puede ilustrar al respecto: "Se presentaron donde él su madre y sus hermanos, pero no podían llegar hasta él a causa de la gente. Le anunciaron: 'Tu madre y tus hermanos están ahí fuera y quieren verte'” (Lc 8,19-20). Madre y hermanos no se identifican. En este caso, si los términos no se distinguen ellos pueden llevarnos fácilmente a la confusión.

Seguidamente, en este grado de la distinción, el apelativo madre y hermana puede ser entendido desde la analogía para indicar dos relaciones esenciales posibles que se dan, uno en el orden de la naturaleza y el otro en el de la comparación o en el sentido figurado. En este caso lo vemos claramente en la respuesta de Jesús a sus interlocutores: "Mi madre y mis hermanos son aquellos que oyen la Palabra de Dios y la cumplen" (Lc 8,21). en este caso no se desmiente lo real de la maternidad y la hermandad de los sujetos. este tipo de relación puede ser visto con otro ejemplo: en su sermón Sobre los pastores, san Agustín dice:

Por ello debo tener presente dos cosas, distinguiéndolas bien, a saber: que por una parte soy cristiano y por otra soy obispo. el ser cristiano se me ha dado como don propio; el ser obispo, en cambio lo he recibido para vuestro bien" (Liturgia de las Horas según el rito Romano, p. 224).

en este sentido literal, María es madre en el orden de la generación y de la fe como don propio de su naturaleza por ser la Madre del Hijo de Dios, pero es hermana nuestra por el beneficio que ha recibido de su pertenencia al grupo de los creyentes, los redimidos.

Por último, este esfuerzo de la distinción tiene como fin situar esta relación de madre y hermana de los pobres en un sentido espiritual. ello implica entonces una claridad terminológica para no encasillar a María en unas imágenes de nuestra experiencia familiar, las cuales quizás de manera particular nos ha tocado vivir; aquí la maternidad y la hermandad de María con respecto a nosotros los creyentes exigen una purificación de nuestras propias figuras de madre y hermano.

María no es un eslabón entre Dios y nosotros, sino el seno privilegiado que nos engendra como hermanos de Cristo. María es el cofre en el que tiene lugar nuestro encuentro directo con Cristo. Si nuestra docilidad a la gracia, si nuestras oraciones a Cristo, las insertamos en el "fiat" 
mariano que hace suyas todas nuestras súplicas: entonces ese "fiat" se convierte en el medio todopoderoso de que nuestras oraciones sean escuchadas (Schillebeeckx, 1969, p. 215).

En una sana reflexión teológica de la mariología y en el aspecto figurativo, María es para nosotros madre de los creyentes y en el orden de la redención una hermana porque formó su humanidad en la gracia. ella nos presta su voz para dirigimos a su Hijo y para cantar las alabanzas de nuestras propias fragilidades, pues en ella no hay mentira. Para finalizar, hago mía la oración de Herder Cámara a la Virgen de la Liberación:

¿qué hay en ti, en tus palabras, en tu voz,

cuando anuncias en el Magnificat

la humillación de los poderosos

y la elevación de los humildes,

la saciedad de los que tienen hambre

y el desmayo de los ricos,

que nadie se atreve a llamarte revolucionaria

ni mirarte con sospecha?

¡Préstanos tu voz y canta con nosotros!

(Descalzo, 1992, p. 105).

\section{Referencias}

Brown, R. e., Fitzmyer, J. y Murphy, R. (2004). Nuevo Comentario Bíblico San Jerónimo. Nuevo Testamento y artículos temáticos. Navarra: Verbo Divino.

Descalzo, J. L. M. (1992). Vida y misterio de Jesús de Nazaret. Salamanca: Sígueme.

Gélin, A. (1994). Los pobres de Yavé. quito: Verbo Divino.

George, A. (1993). María. en Léon-Dufour, X. (ed.). Vocabulario de teología bíblica (pp. 508-513). Barcelona: Herder.

Groupe des Dombes (1999). Marie dans le dessein de Dieu et la communion des Saints. París: Bayard. 
Grelot, P. (1980). Marie (écriture sainte). en Dictionnaire de Spiritualité (t. X, col. 409423). París: Beauchesne (Trabajo original publicado en 1984).

Guijarro Oporto, S. y García, M. S. (1995). Comentario al Nuevo Testamento. Navarra: Verbo Divino y La Casa de la Biblia.

Jeanlin, F. (2012). La Mère de Dieu et les femmes dans 1'économie du salut. Unité des Chrétiens, (9-11).

Jourjon, M. y Meunier, B. (1988). Marie (théologie historique). en Lacoste, J. (ed.). Dictionnaire critique de théologie (pp. 707-715). París: Presses Universitaires de France.

Laurentin, R. (1985). María en la fe cristiana. en Lauret, B. y Refoule, F. (1985). Iniciación a la práctica de la teología. Dogmática 2 (Vol. III) (pp. 433-465). Madrid: Cristiandad.

Liturgia de la Horas, según el rito Romano. (2004). Tomo IV. Bilbao: Desclée de Brouwer.

O’Donnell, C. y Pié-Ninot, S. (2001). Diccionario de eclesiología. Madrid: San Pablo.

Ossanna, T. F. (1988). Madre nuestra. en Fiores, S. y Meo, S. (eds.). Nuevo Diccionario de Teología (pp. 1200-1212). Madrid: San Pablo.

Schillebeeckx, e. (1969). María, madre de la redención. Bases religiosas del misterio de María. Madrid: Fax.

Schillebeeckx, e. (2000). María, ayer, hoy, mañana. Salamanca: Sígueme.

Schmaus, M. (1973). María. en Rahner, K. (ed.). Enciclopedia teológica Sacramentum Mundi (tomo IV) (pp. 425-448). Barcelona: Herder. 
